\title{
Expression pattern of the urokinase-plasminogen activator system in rat DS-sarcoma: Role of oxygenation status and tumour size
}

\author{
M Weinmann*,', O Thews', T Schroeder' and P Vaupel' \\ 'Institute of Physiology \& Pathophysiology, University of Mainz, 55099 Mainz, Germany
}

\begin{abstract}
The urokinase plasminogen activator system plays a central role in malignant tumour progression. Both tumour hypoxia and enhancement of urokinase plasminogen activator, urokinase plasminogen activator-receptor and plasminogen activator inhibitor type I have been identified as adverse prognostic factors. Upregulation of urokinase plasminogen activator or plasminogen activator inhibitor type I could present means by which hypoxia influences malignant progression. Therefore, the impact of hypoxia on the expression pattern of the urokinase plasminogen activator system in rat DS-sarcoma in vivo and in vitro was examined. In the in vivo setting, tumour cells were implanted subcutaneously into rats, which were housed under either hypoxia, atmospheric air or hyperoxia. For in vitro studies, DS-sarcoma cells were incubated for $24 \mathrm{~h}$ under hypoxia. Urokinase plasminogen activator and urokinase plasminogen activator-receptor expression were analysed by flow cytometry. Urokinase plasminogen activator activity was measured using zymography. Plasminogen activator inhibitor type I protein levels in vitro and in vivo were examined with ELISA. PAI-I mRNA levels were determined by RT-PCR. DS-sarcoma cells express urokinase plasminogen activator, urokinase plasminogen activator-receptor, and plasminogen activator inhibitor type I in vitro and in vivo. The urokinase plasminogen activator activity is enhanced in DS-sarcomas compared to normal tissues and rises with increasing tumour volume. The oxygenation level has no impact on the urokinase plasminogen activator activity in cultured DS-sarcoma cells or in solid tumours, although in vitro an increase in plasminogen activator inhibitor type I protein and mRNA expression after hypoxic challenge is detectable. The latter plasminogen activator inhibitor type I changes were not detectable in vivo. Hypoxia has been demonstrated to contribute to the upregulation of some components of the system in vitro, although this effect was not reproducible in vivo. This may indicate that the serum level of plasminogen activator inhibitor type $I$ is not a reliable surrogate marker of tumour hypoxia.
\end{abstract}

British Journal of Cancer (2002) 86, 1355 - |36|. DOI: 10.1038/sj/bjc/6600237 www.bjcancer.com

(c) 2002 Cancer Research UK

Keywords: urokinase plasminogen activator; plasminogen activator inhibitor type-I; urokinase plasminogen activator receptor; hypoxia; DS-sarcoma; malignant progression

Tumour invasion, malignant progression and distant metastasis depend on complex multistep processes. One prerequisite is the ability of tumour cells to initiate extracellular proteolysis which is required for the crossing of tissue barriers, migration, invasion, tissue remodelling and angiogenesis. There is abundant experimental evidence that serine proteases of the urokinase-plasminogen activator system play a major role in malignant progression and tumour metastasis (Andreasen and Petersen, 2000).

The urokinase-plasminogen activator (uPA) is secreted in a zymogen form as inactive single-chain proenzyme (pro-uPA) by tumour and/or by stromal cells and is converted by limited proteolytic cleavage into the active two-chain enzyme. It binds to the urokinase plasminogen activator receptor (uPAR), which is located on the surface of tumour cells, and also on cells of the tumour stroma. The binding to the receptor leads to a massive enhancement of proteolytic activity, providing an efficient and locally focussed proteolysis. The main target of uPA is plas-

*Correspondence: Dr M Weinmann, Department of Radiation Oncology, University of Tübingen, Hoppe-Seylerstrasse 3, 72076 Tübingen, Germany; E-mail: martin.weinmann@med.uni-tuebingen.de

Received 19 November 200I; revised 13 February 2002; accepted 13 February 2002 minogen, which is converted into plasmin. Urokinaseplasminogen activator is also involved in the activation of hepatocyte growth factor/scatter factor (HGF/SF). Plasmin is able to cleave a variety of proteins of the extracellular matrix (ECM) such as collagen type IV, laminin, fibronectin and vitronectin and is also involved in the conversion of some matrix-metalloproteinases from the zymogen pro-form into active enzymes and in the activation of latent TGF $\beta$ or in the release of bFGF from ECMbinding sites.

The proteolytic activity of the $\mathrm{uPA} / \mathrm{uPAR}$ complex is regulated by so-called serpins (plasminogen activator inhibitor type I (PAI1) and type II (PAI-2)). The binding of PAI induces the internalisation of the uPA/uPAR complex, intracellular degradation of uPA and the recycling of the UPAR to the cell membrane (for a review see Andreasen et al, 1997).

An upregulation of uPA and/or uPAR has been described for many human tumours. High levels of uPA and UPAR in tumour tissue (and also in plasma) are associated with poor prognosis of patients with cancers of the breast, head and neck, uterine cervix, bladder, lung, ovary or with soft tissue sarcoma (for a review see Reuning et al, 1998). Paradoxically, many studies also identified enhanced levels of PAI-1, but not PAI-2, as an adverse prognostic factor (Reuning et al, 1998). The role of PAI-1 in tumour progression is not yet fully understood. Additional functions beyond the 
involvement in proteolysis may explain the tumour-promoting role of PAI-1 (Bajou et al, 1998).

So far, the events leading to an enhanced expression of uPA, UPAR or PAI-1 in solid tumours have not been fully elucidated. Cytokines and oncogenes are able to induce components of the uPA-system (Reuning et al, 1998), but the trigger mechanisms for upregulation could also be derived from the specific tumour micro-environment.

Most tumours are characterised by low extracellular $\mathrm{pH}$, glucose depletion, high lactate levels and regions with low oxygen tensions (Vaupel et al, 1989, 1992, 1998). Low oxygen tensions in human tumours have been associated with poor outcome (e.g. Höckel et al, 1993, 1996; Nordsmark and Overgaard, 2000; Nordsmark et $a l, 2001$ ), enhanced local or locoregional spread (Höckel et al, 1999) and enhanced metastatic potential (Brizel et al, 1996; Sundfor and Rofstad, 1998; Rofstad, 2000).

Tumour hypoxia is a key parameter, able to modulate the expression of a variety of genes which are involved in tumour angiogenesis, malignant progression and distant metastasis (Dachs and Tozer, 2000; Koong et al, 2000; Höckel and Vaupel, 2001). Some components of the uPA-system have also been shown to be induced by hypoxia in a number of cell lines in vitro (Graham et al, 1998, 1999; Kietzmann et al, 1999; Maity and Solomon, 2000).

The aim of this study is the characterisation of the expression of UPA, uPAR and PAI-1 in rat DS-sarcoma in vitro and in vivo (i.e., from tumour cell culture to the solid tumour), the identification of the main cellular source in solid DS-tumours and the examination of the dependency of uPA, uPAR and PAI- 1 expression on microenvironmental factors such as oxygenation status.

\section{MATERIALS AND METHODS}

\section{Animals and tumours}

$0.4 \mathrm{ml}$ of haemorrhagic ascites of syngenic DS-sarcoma cells $\left(10^{4}\right.$ cells $\mu \mathrm{l}^{-1}$ ) were injected s.c. into the hind foot dorsum of Sprague Dawley rats (6-8 weeks of age, body weight 180-200 g, Charles River, Sulzfeld, Germany). Tumours were measured daily using precision callipers, and were excised once a volume of between 1 and $2 \mathrm{ml}$ was reached (for experiments evaluating the impact of volume, tumours between 0.5 and $3.5 \mathrm{ml}$ were used). Immediately after excision single cell suspensions were prepared for flow cytometry, or alternately tumours were frozen in liquid nitrogen and stored at $-80^{\circ} \mathrm{C}$. For experiments examining the role of the oxygenation status, animals were housed during the whole period of tumour growth in a hypoxic atmosphere $\left(8 \% \mathrm{O}_{2} / 92 \%\right.$ $\mathrm{N}_{2}$ ), normal room air or under hyperoxic conditions $\left(100 \% \mathrm{O}_{2}\right)$ for 7-12 days. All animal experiments performed had been approved by the regional ethics committee according to German federal law. The ethical guidelines that were followed meet the standards required by the 'United Kingdom Committee on Cancer Research (UKCCCR) guidelines for the welfare of animals in experimental neoplasia' (Workman et al, 1998).

\section{Hypoxic cell culture}

To establish hypoxic conditions in vitro, a gas-proof stainless steel chamber inside an incubator was flushed with a prewarmed and water saturated gas mixture of $\approx 95 \% \mathrm{~N}_{2} / \approx 5 \% \mathrm{CO}_{2}$ and $<0.1 \%$ $\mathrm{O}_{2}$. After an initial peak, the gas flow was adjusted to $0.51 \mathrm{~h}^{-1}$ and the time course of oxygen washout was measured. DS-sarcoma cells were isolated from solid tumours and grown in vitro. For hypoxic challenge of DS-sarcoma cells, three petri dishes $\left(2 \times 10^{5}\right.$ cells ml $^{-1}$ medium, Petri Perm ${ }^{\mathrm{TM}}$, Heraeus, Hanau, Germany) were placed into the hypoxic chamber for $24 \mathrm{~h}$. The hypoxic period commenced $\left(\mathrm{t}_{0}=0 \mathrm{~h}\right)$ when the gas flow was started. Under these conditions, after a wash out period of $2 \mathrm{~h}$, the $\mathrm{O}_{2}$ concentration in the chamber was below $1 \%$. Control cells were incubated under a normal atmospheric oxygen concentration $\left(\mathrm{H}_{2} \mathrm{O}\right.$ saturated room air, 5\% $\left.\mathrm{CO}_{2}\right)$.

\section{Indirect flow cytometry of uPA and uPAR}

Single cell suspensions of solid tumours were prepared and contaminating red blood cells removed using an RBC lysis buffer. The suspension was adjusted to give a concentration of $0.5-$ $1 \times 10^{6} \mathrm{cells} \mathrm{ml}^{-1}$ in phosphate buffered saline supplemented with $1 \%$ glucose, washed twice and stained with either uPA (sc-6831 Santa Cruz Biotech., Santa Cruz, CA, USA), uPAR polyclonal IgG antibody (sc-9795 Santa Cruz Biotech., Santa Cruz, CA, USA) or normal goat IgG antibody (sc-2028 Santa Cruz Biotech., Santa Cruz, CA, USA) as negative controls. Both antibodies were detected with a FITC-labelled donkey anti-goat IgG antibody (sc2024 Santa Cruz Biotech., Santa Cruz, CA, USA) and measured using flow cytometry (Coulter EPICS Profile, Beckman Coulter, Palo Alto, CA, USA).

\section{One-phase uPA zymography}

Whole cell protein extracts were prepared from $20 \mu \mathrm{m}$ cryosections of solid tumours or from washed cell suspensions by incubating the homogenised cell material for $45 \mathrm{~min}$ at $4^{\circ} \mathrm{C}$ in a lysis buffer (0.01 M HEPES, $0.25 \mathrm{M}$ Sucrose, $0.5 \% \mathrm{v} \mathrm{v}^{-1}$, Triton X-100, $\mathrm{pH}$ 7.2). Debris was removed by centrifugation $(15000 \times g)$ for $15 \mathrm{~min}$ at $4^{\circ} \mathrm{C}$ and supernatants were stored at $-80^{\circ} \mathrm{C}$. Protein content was determined by a DC protein assay (BioRad, Hercules, CA, USA) and adjusted to $1 \mathrm{mg} \mathrm{ml}^{-1}$ for zymography. Seven $\mu \mathrm{l}$ of cell lysates or cell culture supernatants were run on a $10 \%$ SDS PAGE containing $0.3 \%$ casein and $0.025 \mathrm{U} \mathrm{ml}^{-1}$ Lys-plasminogen under non-reducing conditions together with prestained molecular weight markers (BioRad, Hercules, CA, USA). Gels were washed after electrophoresis in a washing buffer (Triton X-100 $2.5 \%$, $0.1 \mathrm{M}$ TRIS - HCl, $\mathrm{pH} 8.1$ ) for $2 \times 15 \mathrm{~min}$ and incubated overnight in $10 \mathrm{mM} \mathrm{CaCl}_{2}, 50 \mathrm{mM}$ TRIS- $\mathrm{HCl}(\mathrm{pH} 8.1)$ at room temperature. The gels were stained with $0.1 \%$ Coomassie Blue, so that zones of uPA activity occurred as clear lysis zones on a blue background. The bands were quantified densitometrically (Bio IQ Quantifier, B.I. Systems Corporation, Ann Arbor, MI, USA). For controls, parallel samples were loaded on gels without plasminogen. To specifically determine uPA levels also control gels which contained $2 \mathrm{~mm}$ amiloride were also used. Amiloride selectively inhibits uPA but does not affect other plasminogen activators (Vassalli, 1987).

\section{PAI-1 - ELISA}

Whole cell protein lysates were prepared as described above. PAI-1 protein concentration in cell culture supernatant, Triton extracts (0.01 M HEPES, $0.25 \mathrm{M}$ Sucrose $0.5 \% \mathrm{v} \mathrm{v}^{-1}$, Triton X-100, $\mathrm{pH}$ 7.2) of solid DS-sarcomas or DS-sarcoma cells in culture, or in rat serum have been determined by a rat-specific PAI-1 sandwich ELISA (American Diagnostica, Pfungstadt, Germany) according to the manufacturer's recommendations.

\section{RT - PCR analysis}

RNA extraction RNA was isolated from washed cell suspensions or cryosections of solid DS-sarcomas by the guanidinium isothiocyanate method using the Qiagen RNeasy extraction kit (Qiagen, Hilden, Germany) according to the manufacturer's recommendations. RNA content and purity was determined by photometry at 260 vs $280 \mathrm{~nm}$.

Reverse transcription $1 \mu \mathrm{g}$ of total RNA was incubated with 50 pmoles of random hexamers for $15 \mathrm{~min}$ at $65^{\circ} \mathrm{C}$. The mixture 
was subsequently cooled on ice for $5 \mathrm{~min}$, then the RT-mix was added containing PCR-buffer, $1 \mathrm{U}$ Rnase inhibitor, $15 \mathrm{U}$ MuLV reverse transcriptase, $10 \mathrm{mM} \mathrm{MgCl}_{2}, 1 \mathrm{~mm}$ PCR nucleotide mix and double-distilled water up to a volume of $30 \mu \mathrm{l}$ (all biochemicals from Applied Biosystems, Welterstadt, Germany, except dNTP which was supplied by Roche, Mannheim, Germany). Reverse transcription was carried out in a thermal cycler (Biometra, Göttingen, Germany) for $1 \mathrm{~h}$ at $40^{\circ} \mathrm{C}$ with an additional 5 min-step at $99^{\circ} \mathrm{C}$ for inactivation of the reverse transcriptase. cDNA was subsequently stored at $-20^{\circ} \mathrm{C}$.

PCR primers For pseudogene-free amplification of rat $\beta$-actin cDNA, previously published primers have been used (Raff et al, 1997) ( $\beta$-actin sense: $_{\text {acaacctccttgcagctcc, } \beta \text {-Actin }}$ antisense: ggatcttcatgaggtagtctgtc). PAI-1 primers were constructed from published sequences of the rat genome (Genbank accession no. M24067 (Brudzinski et al, 1990) PAI-1 $1_{\text {sense: ttgggaaagggttcgcttc }}$ PAI- $1_{\text {antisense: }}$ agtcgttgatgatgaatctgg, intron spanning). Sequence identity of the constructed primers was checked by excising bands from the gel, followed by DNA sequencing. Negative controls with RT (-)-template were carried out to check possible co-amplification of genomic DNA.

PCR Following an initial denaturation period of 3 min at $95^{\circ} \mathrm{C}$, PCR was carried out in a thermal cycler (Biometra, Göttingen, Germany) at $95^{\circ} \mathrm{C} / 30 \mathrm{~s}, 60^{\circ} \mathrm{C} 1 \mathrm{~min}$ and $72^{\circ} \mathrm{C} / 30 \mathrm{~s}$. A final extension period of $72^{\circ} \mathrm{C} / 7$ min was performed at the end of each PCR reaction. One PCR sample of $25 \mu \mathrm{l}$ volume contained a mixture of $2.4 \mathrm{mM} \mathrm{MgCl}_{2}$ and PCR buffer (Applied Biosystems, Welterstadt, Germany), $0.8 \mathrm{mM}$ dNTP-mix (Roche, Mannheim, Germany) and $0.1 \mu \mathrm{g}$ cDNA. PCR primers were added up to an amount of 10 pmol each.

Fragment detection and evaluation One per cent agarose gels stained with ethidium bromide were run for 90 min at $60 \mathrm{~V}$. PCR products were visualized on a UV-screen by means of a digital camera and attached hardware (Intas, Göttingen, Germany). Densitometrical evaluation was performed using image processing software (Bio IQ Quantifier, B.I. Systems Corporation, Ann Arbor, MI, USA). To ensure the specificity of the amplification $\beta$-actin and PAI-1 band were excised from the gel and sequenced.

Semi-quantitative multiplex $R T-P C R$ For a semi-quantitative analysis of PAI-1 mRNA in solid tumour or isolated DS-sarcoma cells in vitro, a non-competitive RT-PCR method in the presence of two pairs of primers for PAI- 1 mRNA and for $\beta$-Actin mRNA as internal standard was performed. Each PCR-mix was split into six fractions, undergoing PCR for 18,21, 24, 27, 30 or 33 PCR cycles respectively, followed by agarose gel electrophoresis and densitometry. After plotting the data-points (band intensity) vs PCR-cycles, curve fits were performed on the computer in order to generate a PCR-amplification curve for every target. For each amplification graph, a threshold cycle number was extrapolated, corresponding to a threshold value just above the densitometrical background. For every specimen, the calculated difference between the respective threshold cycle of $\beta$-actin and PAI- 1 was regarded as a measure of PAI-1 gene expression: $\Delta$ PAI-1=PAI-1[threshold cycle no.] $-\beta$-actin [threshold cycle no.]

\section{Statistical analysis}

Urokinase plasminogen activator and UPAR expression on the cell surface compared to negative controls were analysed with a paired sample $t$-test. Zymographic uPA activity in the different groups was analysed by a Wilcoxon test for paired samples, and PAI-1 protein concentration in the different groups of samples was compared by the Mann-Whitney test using SPSS 10.0 statistical software.

\section{RESULTS}

\section{Expression of UPA, UPAR and PAI-1 by DS-sarcoma cells}

Expression of uPA, PAI-1 and UPAR was examined in solid DSsarcoma and in DS-sarcoma cells in vitro. Surface expression of uPAR and uPA was detected in both DS-sarcoma cells derived from cell culture (Figure 1) and, to a comparable extent, on cells isolated from solid DS-sarcomas (data not shown). Histological examination of DS-sarcomas demonstrated that the proportion of tumour stroma is quite low in these tumours and the comparison of the UPA and uPAR surface expression by flow cytometry exhibits no significant difference in the mean fluorescence activity between DS-tumour cells isolated from solid tumours and DSsarcoma cells grown in culture. This indicates that most of uPA and $\mathrm{UPAR}$ in the samples derives from tumour cells, rather from leukocytes or stromal cells.

The zymography of crude whole cell protein extracts $(7 \mu \mathrm{g} /$ total protein per sample) from solid DS-sarcomas exhibited two plasminogen-dependent proteolytic bands, one with strong, another with weak proteolytic activity in the $50 \mathrm{kDa}$ region. Adding $2 \mathrm{~mm} / \mathrm{ml}$ amiloride to the SDS-PAGE abrogates the proteolytic activity of the strong lysis zone completely, while the weak band was not influenced at all, indicating that this strong lysis zone represents the proteolytic activity of uPA (Figure 2). Similar bands were found in protein extracts of DS-sarcoma cells in vitro (data not shown).

DS-sarcoma cells also express PAI-1. Plasminogen activator inhibitor type 1 protein could be detected in total protein extracts of solid DS-tumours, but also in whole cell lysate of cultured DSsarcoma cells (by ELISA). The highest amount of PAI-1 protein was found in cell culture supernatants of DS-sarcoma cells in vitro.

Not only PAI-1 protein but also PAI-1 mRNA was found in both RNA extracts from solid DS-tumours and RNA extracts of DS-sarcoma cells in vitro by RT - PCR, indicating that PAI-1 is also produced by the tumour cell itself. Since RT-PCR reactions with PAI-1 primers showed no co-amplification of genomic DNA, the possibility of false positive results can thus be disregarded.

\section{uPA activity in DS-sarcoma cells in vitro and in solid tumours}

Urokinase plasminogen activator activity was detectable in solid DS-sarcoma and in DS-sarcoma cells in vitro. There was no significant difference in band intensity when lysates from solid tumour

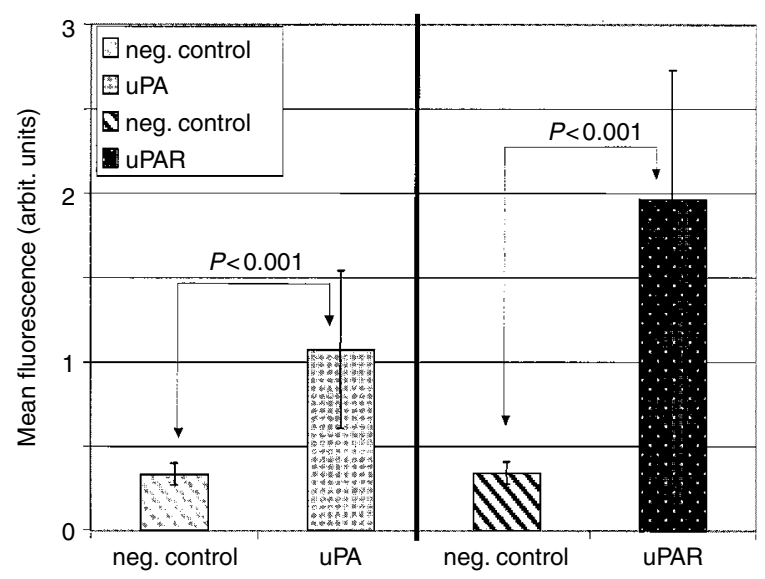

Figure I Surface expression of UPA and UPAR on DS-sarcoma cells determined by flow cytometry. There are significant differences in mean fluorescences between UPA or UPAR labelled cells and cells labelled with idiotypic negative controls ( $n=35$ per group, means \pm I s.d.). 
tissue were compared with whole cell protein lysates from DSsarcoma cells cultured in vitro. This may indicate that in solid DS-sarcomas the tumour cells and not the stromal cells contribute mainly to the proteolytic activity of uPA.

The uPA activity in solid DS-sarcomas was compared to the activity in various normal tissues (lung, skeletal muscle, kidney, liver) by zymography. All normal tissues exhibited some degree of uPA activity. The amount of uPA expression varied significantly between the different tissues with low activity being found in skeletal muscle and liver in contrast to higher activities in kidney and lung. In tumour tissue the uPA activity was much higher than in any type of normal tissue examined. Standardised on $7 \mu \mathrm{g}$ total protein per sample, the uPA activity in DS-sarcoma was 4-20 fold higher than in the normal tissues examined (Figure 3 ).

\section{The impact of the oxygenation status on UPAR protein expression and overall uPA activity}

To examine the impact of the tumour oxygenation status on uPA activity in vivo, a set-up for long-term inspiratory hypoxia was used. Immediately after tumour implantation, rats were housed in a hypoxic atmosphere containing $8 \% \mathrm{O}_{2} / 92 \% \mathrm{~N}_{2}$. Tumours

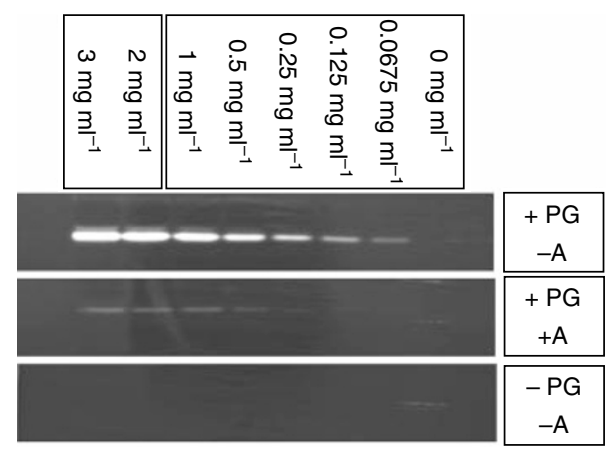

Figure 2 uPA activity in whole cell lysates of DS-sarcoma (0$3 \mathrm{mg} \mathrm{ml}^{-1}$ whole cell protein per sample) determined by I-phase zymography. Lysis zones in the $50 \mathrm{kD}$ region (+PG/ $-\mathrm{A}$ ) are abrogated in gels without plasminogen $(-P G /-A)$ or by inhibition with amiloride (+PG/ $+\mathrm{A})$.

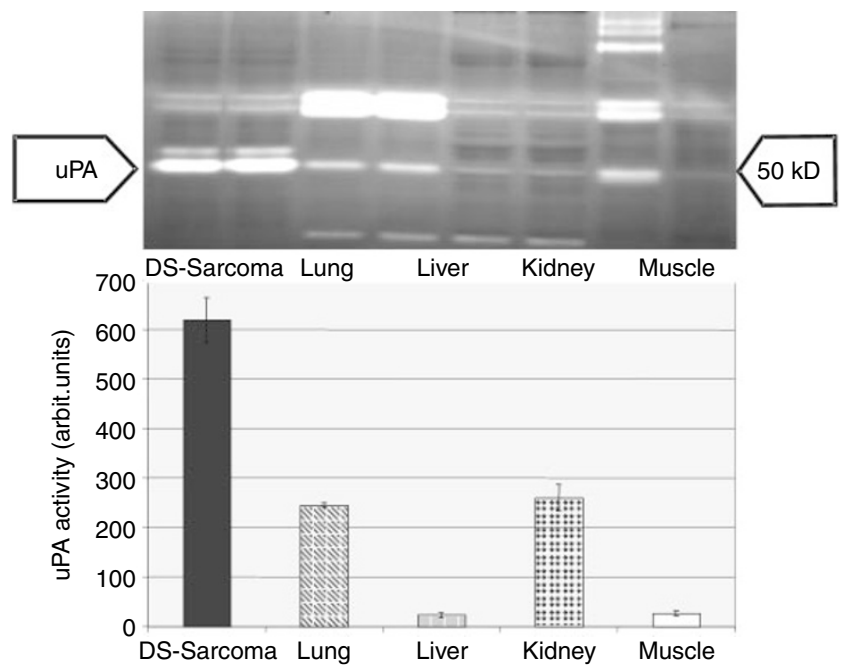

Figure 3 uPA activity in solid DS-sarcomas (assessed by zymography) compared to various rat normal tissues ( $n=6$ per group, means \pm I s.d. $P<0.00$ I. DS-sarcoma vs liver and skeletal muscle; $P<0.01$, DS-sarcoma vs lung and kidney). were compared to those in control animals breathing normal air or $100 \% \mathrm{O}_{2}$ during the whole period of tumour growth.

In a preceding study the oxygenation of DS-sarcomas under these conditions was determined by computerised $\mathrm{pO}_{2}$ histography. Mean median $\mathrm{pO}_{2}$ of DS-sarcomas grown in air was about $5 \mathrm{~mm}$ $\mathrm{Hg}$ and significantly decreased to $2 \mathrm{~mm} \mathrm{Hg}$ upon inspiration of $92 \% \mathrm{~N}_{2} / 8 \% \mathrm{O}_{2}$ (Kelleher et al, 1997), whereas breathing of pure oxygen led to a significant increase in the mean median $\mathrm{pO}_{2}$ up to approximately $80 \mathrm{~mm} \mathrm{Hg}$ (Thews et al, 1997). Various adaptive processes can be expected to take place during long-term exposure of the animals to a hypoxic atmosphere $\left(8 \% \mathrm{O}_{2}\right)$. Under these conditions, animals showed a polyglobulia with a RBC count of $8.4 \times 10^{6} / \mu \mathrm{l}$. The increased haematocrit however, results in a higher viscous resistance to flow which might worsen microcirculation under these conditions. Due to adaption, the mean $\mathrm{pO}_{2}$ in tumours of chronically hypoxic rats was slightly higher $(3 \mathrm{mmHg})$ compared to acute hypoxia, however still significantly lower compared to air breathing animals. There were no indications for significant improvements of tumour oxygenation by adaptive mechanisms under low oxygen breathing conditions for days.

Using zymography, the uPA activity in solid DS-sarcomas was compared between solid tumours which were grown under inspiratory hypoxia, normal room air or hyperoxia and in DS-sarcoma cells in vitro which were incubated either under hypoxic or normoxic conditions. Under in vitro and in vivo conditions the uPA activity was comparable (Figure 4).

The surface expression of uPAR was measured in single cell suspensions derived from solid DS-sarcomas. Mean fluorescence of DS-sarcoma cells was about 5-10 times higher than the background activity of the negative controls and even higher than the signals derived from uPA expression (Figure 1). To evaluate the impact of tumour oxygenation, uPAR expression of tumour cells from solid tumours grown under $8 \% \mathrm{O}_{2} / 92 \% \mathrm{~N}_{2}$ was compared to uPAR expression in tumours grown in normal room air. There was no enhanced surface expression in the hypoxic group compared to tumours grown in normal air $(n=50$ per group, data not shown). Therefore, a second series of hypoxic tumours $(n=14$ grown under $8 \% \mathrm{O}_{2} / 92 \% \mathrm{~N}_{2}$ - data not shown) was compared to tumours $(n=14)$ grown in rats which were housed in $100 \% \mathrm{O}_{2}$ to achieve greater differences in the oxygenation. In this latter series,

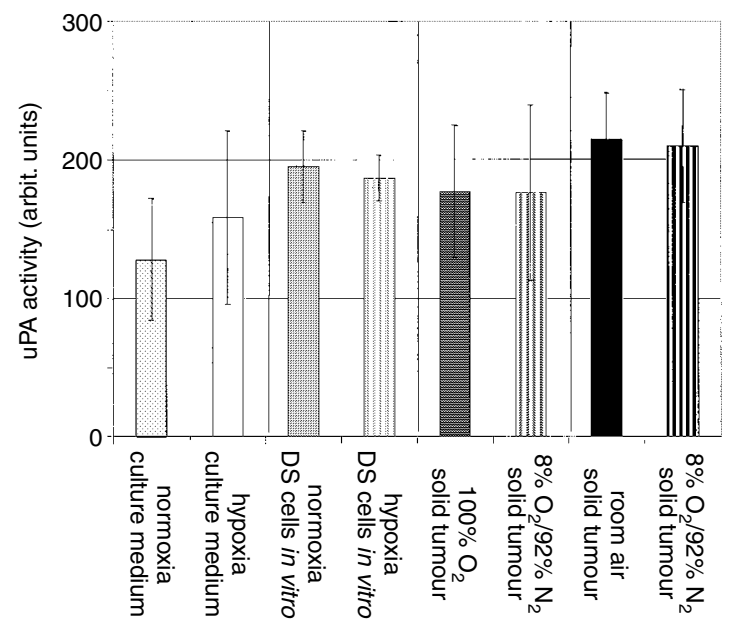

Figure 4 Impact of the oxygenation status on uPA activity in DS-sarcoma cells in vitro and in solid tumours: In the supernatant, in whole cell lysates of DS-sarcoma cells and in solid tumours the uPA activity was not significantly different under various conditions of $\mathrm{O}_{2}$ availability (culture medium: eight independent samples/group, DS-sarcoma cell lysates: five independent samples/group; solid tumours: inspiratory hypoxia $\left(8 \% \mathrm{O}_{2} / 92 \% \mathrm{~N}_{2}\right)$ vs room air in vivo: $n=50 /$ group, inspiratory hypoxia $\left(8 \% \mathrm{O}_{2} / 92 \% \mathrm{~N}_{2}\right)$ vs hyperoxia $\left(100 \% \mathrm{O}_{2}\right): n=\mid$ 4/group; values are means \pm Is.d.) 
again also no significant difference in uPAR expression could be detected by flow cytometry.

\section{Impact of tumour volume on uPA activity}

No differences in uPA activity were detected between tumours grown under different $\mathrm{O}_{2}$ conditions when the tumour size was equally distributed between the groups. To evaluate the impact of tumour volume, whole cell protein extracts of early stage small tumours $(0.5-1 \mathrm{ml}$ tumour volume) were compared to more advanced tumours (volumes of 2.0-3.5 ml). Each group encompassed samples from 16 different tumours. We found a significant, positive correlation between uPA activity and tumour volume. The band intensity standardised on total protein concentration per sample was substantially higher in the larger tumours than in the smaller tumours $(P=0.0001$, Figure 5$)$. The differences in tumour oxygenation between small and large tumours in this series has not been evaluated, but earlier measurements indicated that the mean $\mathrm{pO}_{2}$ is decreased in larger experimental tumours compared to smaller ones.

\section{Impact of hypoxia on PAI-1 mRNA and protein levels}

Plasminogen activator inhibitor type 1 , the proteolytic antagonist of uPA, was analysed on the protein and mRNA level. To evaluate the impact of hypoxia on PAI-1 protein expression in vitro, PAI-1 protein was measured in supernatant of DS-sarcoma cells in vitro grown under hypoxia for $24 \mathrm{~h}$ compared to control cultures (normoxic conditions).

In supernatants of DS-sarcoma cells after hypoxic challenge a two-fold increase of PAI-1 protein concentration was detected by ELISA in five independent experiments (Figure 6), 200000 cells / $\mathrm{ml}$ were used. After $24 \mathrm{~h}$, the number of DS-sarcoma cells almost doubled in normoxic controls, while hypoxia delayed cellular growth, so that the number of cells in hypoxic cultures increased only by $10-50 \%$ in that time period. The effect of hypoxia may therefore, be even more pronounced when the secretion rate of single cells is considered.

In the same experiments semi-quantitative multiplex RT-PCR was used to determine whether this effect could additionally be observed on the mRNA level. The amount of PAI-1 mRNA was estimated as a ratio of PAI- $1 / \beta$-actin mRNA in DS-sarcoma cells

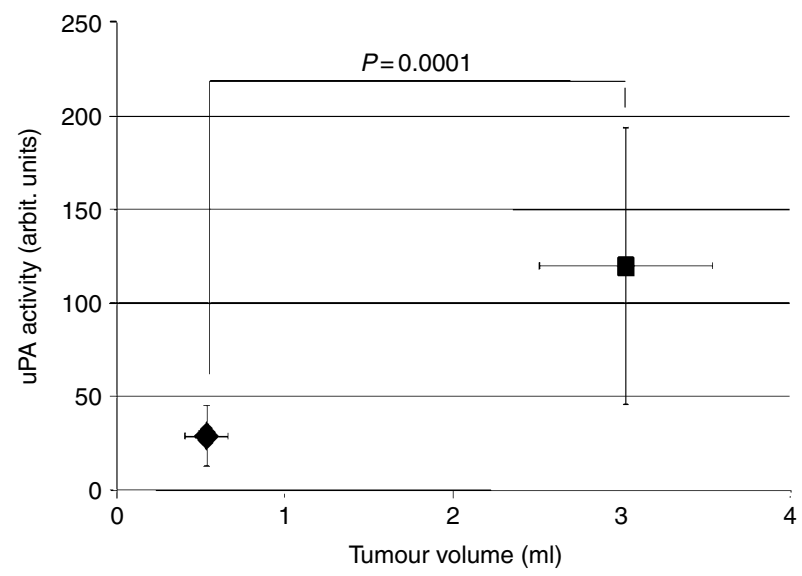

Figure 5 Impact of tumour volume on uPA activity in solid DS-sarcomas, UPA activity measured by one-phase zymography is significantly greater in large tumours $(>2 \mathrm{ml})$ compared to small tumours $(<\mid \mathrm{ml})$ ( $n=16$ per group, values are means \pm I s.d.) (mean $\mathrm{pO}_{2}$ in small tumours (mean vol. $0.5 \mathrm{ml}$ ): $10.6+3.9 \mathrm{mmHg}$, hypoxic fraction $\left(\mathrm{pO}_{2}\right.$-values $\leqslant 2.5 \mathrm{mmHg}$ : $33 \pm 6 \%$ ); mean $\mathrm{pO}_{2}$ in large tumours (mean vol. $2.5 \mathrm{ml}$ ): $2.5 \pm 0.4 \mathrm{mmHg}$, hypoxic fraction ( $\mathrm{pO}_{2}$-values $\leqslant 2.5 \mathrm{mmHg}$ : $52 \pm 3 \%$ ). in vitro immediately after exposure to hypoxia for $24 \mathrm{~h}$. After hypoxic challenge, PAI-1 bands were detected about $2-3$ cycles earlier in relation to the internal $\beta$-actin standard than in normoxic controls. This effect was reproducible in three independent experiments (Figure 7).

The impact of the tumour oxygenation status on PAI-1 protein and mRNA concentrations was also analysed in vivo using inspiratory hypoxia $\left(8 \% \mathrm{O}_{2} / 92 \% \mathrm{~N}_{2}\right)$, room air or hyperoxia $\left(100 \% \mathrm{O}_{2}\right)$ as described above. In each in vivo-experiment PAI-1 protein was measured in whole cell protein extracts of solid DS-tumours, and

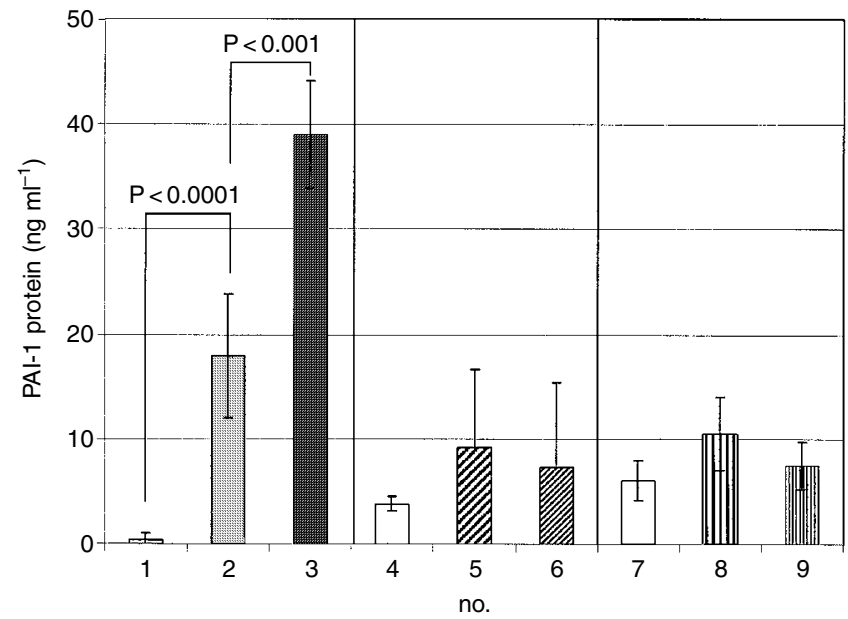

Figure $6 \mathrm{PAl}-\mathrm{I}$ protein concentration in unconditioned culture medium no. I compared to culture medium of DS-sarcoma cells grown under normoxia no. 2 or under $24 \mathrm{~h}$ exposure to hypoxia no. 3. PAl-I protein concentration in sera of healthy rats in normal room air no. 4 compared to sera of rats with solid DS-sarcoma housed under inspiratory hyperoxic ( $100 \%$ $\left.\mathrm{O}_{2}\right)$ no. 5 or hypoxic $\left(8 \% \mathrm{O}_{2} / 92 \% \mathrm{~N}_{2}\right)$ no. 6 conditions. PAl- I protein concentration in solid DS-sarcomas grown under room air no. 7, inspiratory hypoxia $\left(8 \% \mathrm{O}_{2} / 92 \% \mathrm{~N}_{2}\right)$ no. 8 or hyperoxia $\left(100 \% \mathrm{O}_{2}\right)$ no. 9 measured by ELISA. (Values are means \pm I s.d.).

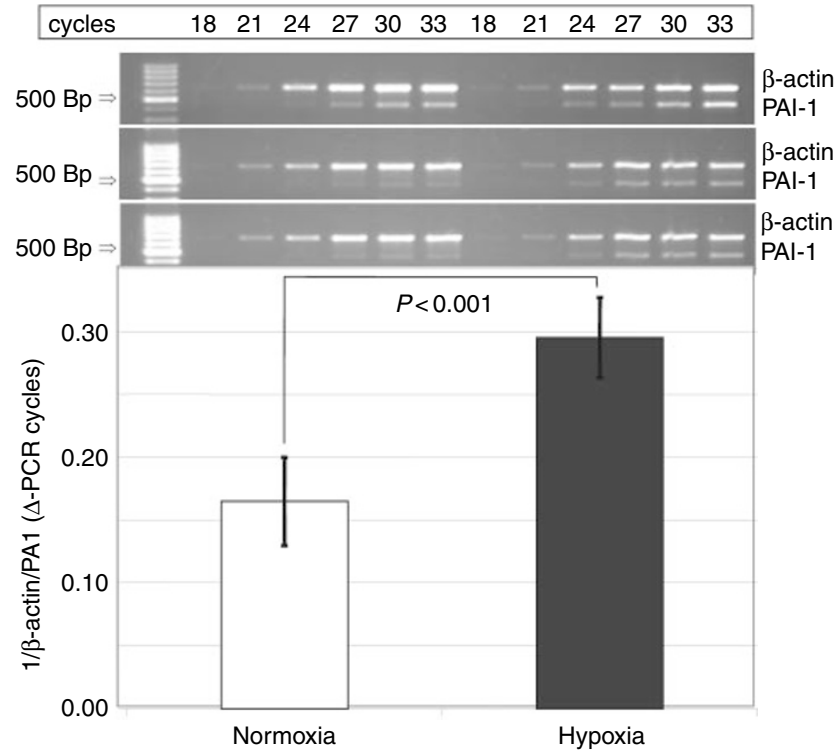

Figure $7 \mathrm{PAl}-\mathrm{I}$ mRNA expression in DS-sarcoma cells in vitro after $24 \mathrm{~h}$ of hypoxia, compared to control cells under normoxic conditions (calculated as I/(band int. $(\beta$-actin -PAl-I)) ( \pm I s.d.)). Hypoxia enhances PAlI mRNA expresssion (PAl-I band emerges 2.88 cycles earlier from the background (mean) compared to normoxic controls using $\beta$-actin as internal standard). 
in the serum of rats housed under one of the breathing conditions chosen after tumour inoculation. The individual serum levels of PAI-1 as well as the amount of PAI-1 protein in DS-tumours were quite variable, but there were no significant differences between the median or mean values of both groups. RT - PCR also failed to detect a significant difference in mRNA expression between tumours grown under hypoxic or hyperoxic conditions (data not shown).

\section{DISCUSSION}

We detected UPA, uPAR and PAI-1 in solid DS-sarcomas in vivo and in primary cultures of DS-sarcoma cells in vitro. In contrast to some other tumour entities (Andreasen et al, 1997), in DSsarcomas the tumour cells themselves generate all three components of the uPA system. Urokinase plasminogen activatorreceptor is expressed on the cell surface of DS-sarcoma cells in vitro or on single cell suspensions derived from solid tumours, PAI-1 protein and mRNA are detectable in solid tumours and DS-sarcoma cells in vitro. Urokinase plasminogen activator activity in whole cell extracts from DS-sarcoma cells in vitro and from solid DStumours in vivo is similar, indicating that the tumour cells are the main source of uPA activity. Therefore, a co-operation between tumour and stromal cells, with different cell types providing different components of the uPA system (as described, for instance, in colon cancer (Sordat el al, 1997)), is not necessarily a prerequisite for the functionality of the uPA system in DS-sarcoma. The uPA activity in DS-sarcomas is significantly higher than in all other normal tissues examined, which may be an indication for its functional role in tumour progression.

The question arises as to which mechanism can up-regulate uPA-induced proteolysis under pathological conditions in malignant tumours. The higher expression may be a result ultimately deducible from oncogenic transformation. A wide variety of hormones, growth factors and cytokines are up-regulated as a consequence of oncogenic transformation and are known to regulate the expression of components of the uPA system (Andreasen et al, 1997). But a further pathway not directly related to oncogenic alterations can not yet ruled out. The special conditions of the tumour micromilieu, especially tumour hypoxia, are known to have an impact on the expression of a variety of genes and the activity of many gene products (Dachs and Tozer, 2000; Koong et al, 2000; Semenza, 2000; Höckel and Vaupel, 2001).

In the present study, incubation of DS-sarcoma cells for $24 \mathrm{~h}$ under hypoxia in vitro induced a significant up-regulation of PAI-1 protein and mRNA. These results are consistent with the observation that PAI-1 is enhanced in cells lacking a functional von-Hippel-Lindau (VHL) gene (Los et al, 1999). pVHL triggers the proteolytic degradation of the hypoxia-inducible factor subunit $1 \alpha($ HIF- $1 \alpha)$ via an ubiquitin-proteasome pathway thereby regulating the transcriptional activity of the most important hypoxiainducible transcription factor. In pVHL deficient cells, HIF-1 is constitutively upregulated; therefore these cells might behave in some aspects like cells under hypoxic stress.

At a glance, the relation between hypoxia and PAI-1 upregulation seems paradoxical, because the role of PAI-1 as an inhibitor of UPA proteolytic function may also suggest that PAI-1 is predominantly an inhibiting factor of malignant progression in general. However, clinical data contradict this assumption. Far more studies report a positive correlation between high expression of PAI-1 and negative outcome than vice versa (Reuning et al, 1998).

Although PAI-1 inhibits proteolytic activity of uPA, this molecule seems to be a marker of aggressiveness in malignant tumours. PAI-1 mRNA is not detectable in low-grade astrocytoma or normal brain tissue by Northern blot, but it is increased in high-grade astrocytomas, and is most pronounced in glioblastoma multiforme (Yamamoto et al, 1994). Further biological functions of PAI-1 beyond involvement in proteolysis and extracellular matrix
(ECM) degradation may explain this paradoxical finding. There are indications that PAI-1 may be crucial for neoangiogenesis in tumours. Impaired tumour growth and reduced angiogenesis have been described in PAI-1 deficient host mice (Bajou et al, 1998).

Plasminogen activator inhibitor type 1 is also related to cell adhesion and motility (Stahl, 1997), and can interfere with the binding between cells and proteins of the extracellular matrix. It reduces the binding between $\mathrm{UPAR}$ and vitronectin $(\mathrm{VN})$, and also the binding between integrins of the $\alpha_{\mathrm{v}}$ family by masking a somatomedin B-like domain (Chapman, 1997). In neuroblastoma, PAI-1 is positively correlated with metastatic behaviour. Sugiura et al (1999) explained this effect by the action of PAI-1 as an antidetachment factor which interrupts the binding to vitronectin and enhances migration toward fibronectin-rich matrices.

Recent experiments described an anti-apoptotic effect of PAI-1 on tumour and benign cell lines (Kwaan et al, 2000). In the present study, DS-sarcoma were seen to be able to survive hypoxic stress, when they had already passed through several cycles of hypoxia and reoxygenation. The relevance of PAI-1 in this phenomenon still has to be determined, but it may be possible that the upregulation of PAI-1 in hypoxia promotes malignant progression and metastasis formation also by additionally increasing resistance to apoptosis (Höckel et al, 1999).

In vitro assays for invasion showed that not the absolute amount of a single component, but rather the optimal relation between uPA, uPAR and PAI-1 is important for the ability of tumour cells to invade ECM matrixes (for a review see Andreasen et al, 1997). Although hypoxia enhances PAI-1 expression in vitro, the uPA activity in whole cell lysates or culture supernatants was not diminished.

These in vitro effects could not be detected in vivo under the conditions described above. The reason for the discrepancy between the in vitro and in vivo results is not yet clear. Tumour oxygenation in vivo is spatially quite heterogeneous, even within a single tumour, and also varies over time. In addition to diffusion-limited (chronic) hypoxia in tumours, changes in vascular patency can generate areas of ischaemic (acute) hypoxia (for a review see Vaupel et al, 1989). Therefore, RT - PCR or ELISA are probably not able to detect such differences in vivo, because they provide only a 'global picture' of protein or mRNA expression at a distinct point in time.

Another reason could be that even globally well-oxygenated tumours exhibit microareas of hypoxia, which can lead to an induction of gene expression. In air breathing animals, solid DSsarcomas exhibit mean $\mathrm{pO}_{2}$ values of about $5 \mathrm{~mm} \mathrm{Hg}$, which is apparently low compared to normal tissue, but which is comparable to the oxygenation values of a variety of human tumours measured in clinical situations. Upon breathing $100 \% \mathrm{O}_{2}$, the mean $\mathrm{pO}_{2}$ of DS-sarcomas could be significantly improved, but poorly oxygenated microareas may still exist under such experimental conditions. Kietzmann et al (1999) found, that the incubation of cells in an $8 \% \mathrm{O}_{2}$ atmosphere is able to induce PAI-1 mRNA in rat hepatocytes in vitro, which indicates that probably even rather moderate degrees of tumour hypoxia may able to enhance PAI-1 expression. In any case this result also indicates that global parameters (such as PAI-1 or VEGF serum levels) may not be a very reliable marker of tumour hypoxia.

In vivo, uPA activity in DS-sarcomas was found to strongly correlate with tumour volume. Small tumours exhibited a significantly lower uPA activity per $\mathrm{mg}$ extracted whole cell protein than larger tumours. This may be an indication that uPA activity is not only involved in early events such as basement membrane degradation during transition from in situ carcinomas to invasive tumours, but also in later events of malignant progression such as invasion of tissue barriers or intravasation/extravasation of tumour cells.

The increase of uPA activity with tumour size could be a result of an autocrine and/or paracrine positive feedback loop within a solid tumour. TGF $\beta$ is a possible candidate for a cytokine involved 
in such a loop. It is converted from a latent into an active form by plasmin-derived proteolysis, and active TGF $\beta$ induces an up-regulation of uPA transcription. However, a hostile tumour micromilieu in larger tumours could also be responsible for this effect. The proportion of hypoxic areas, or areas with poor blood supply, glucose depletion and extracellular acidosis, increases with tumour size in experimental tumours and may also lead to an up-regulation of uPA activity.

In conclusion, these results suggest that the components of the uPA system are up-regulated in rat DS-sarcoma. Micromilieu factors such as hypoxia may contribute to the upregulation of some components of the system, although in this study the in vitro results could not be reproduced in the in vivo system. The expression pattern of components of the uPA system in different tumour

\section{REFERENCES}

Andreasen PA, Kjoller L, Christensen L, Duffy MJ (1997) The urokinase-type plasminogen activator system in cancer metastasis: a review. Int $J$ Cancer 72: $1-22$

Andreasen PA, Petersen HH (2000) The plasminogen activation system in tumor growth, invasion and metastasis. Cell Mol Life Sci 57: 25-40

Bajou K, Noel A, Gerard RD, Masson S, Brunner N, Holst Hansen C, Skobe M, Fusenig NE, Carmeliet P, Collen D, Foidart JM (1998) Absence of host plasminogen activator inhibitor 1 prevents cancer invasion and vascularization. Nat Med 4: $923-928$

Brizel DSJ, Harrelson JM, Layfield LJ, Bean JM, Prosnitz LR, Dewhirst MW (1996) Tumor oxygenation predicts for the likelyhood of distant metastases in human soft tissue sarcoma. Cancer Res 56: $941-943$

Brudzinski CR, MF Nordby EC, Suter SM, Gelehrter TD (1990) Isolation and characterization of the rat plasminogen activator inhibitor-1 gene. J Biol Chem 265: $2078-2085$

Chapman H (1997) Plasminogen activators, integrins, and the coordinated regulation of cell adhesion and migration. Curr Opin Cell Biol 9: 714-724

Dachs GU, Tozer GM (2000) Hypoxia modulated gene expression: angiogenesis, metastasis and therapeutic exploitation. Eur J Cancer 36: 1649-1660

Graham CH, Fitzpatrick TE, McCrae KR (1998) Hypoxia stimulates urokinase receptor expression through a heme protein-dependent pathway. Blood 91: $3300-3307$

Graham CH, Forsdike J, Fitzgerald CJ, Macdonald Goodfellow S (1999) Hypoxia-mediated stimulation of carcinoma cell invasiveness via upregulation of urokinase receptor expression. Int J Cancer 80: 617-623

Höckel M, Knoop C, Schlenger K, Vorndran B, Baussmann E, Mitze M, Knapstein PG, Vaupel P (1993) Intratumoral pO2 predicts survival in advanced cancer of the uterine cervix. Radiother Oncol 26: 45-50

Höckel M, Schlenger K, Aral B, Mitze M, Schäffer U, Vaupel P (1996) Association between tumor hypoxia and malignant progression in advanced cancer of the uterine cervix. Cancer Res 56: 4509-4515

Höckel M, Schlenger K, Höckel S, Vaupel P (1999) Hypoxic cervical cancers with low apoptotic index are highly aggressive. Cancer Res 59: 4525-4528

Höckel M, Vaupel P (2001) Tumor hypoxia: definitions and current clinical, biologic and molecular aspects. J Natl Cancer Inst 93: 266-276

Kelleher DK, Thews O, Vaupel P (1997) Hypoxyradiotherapy: lack of experimental evidence for a preferential radioprotective effect on normal versus tumor tissue as shown by direct oxygenation measurements in experimental sarcoma. Radiother Oncol 45: $191-197$

Kietzmann T, Roth U, Jungermann K (1999) Induction of the plasminogen activator inhibitor-1 gene expression by mild hypoxia via a hypoxia response element binding the hypoxia-inducible factor-1 in rat hepatocytes. Blood 94: 417741-417785

Koong AC, Denko NC, Hudson K, Schindler C, Swiersz L, Koch C, Evans S, Ibrahim H, Le QT, Terris DJ, Giaccia AJ (2000) Candidate genes for the hypoxic tumor phenotype. Cancer Res 60: 883-837

Kwaan HC, Wang J, Svoboda K, Declerck PJ (2000) Plasminogen activator inhibitor 1 may promote tumour growth through inhibition of apoptosis. Br J Cancer 82: 1702-1708

Los M, Zeamari S, Foekens JA, Gebbink MF, Voest EE (1999) Regulation of the urokinase-type plasminogen activator system by the von HippelLindau tumor suppressor gene. Cancer Res 59: 4440-4445

Maity A, Solomon D (2000) Both increased stability and transcription contribute to the induction of the urokinase plasminogen activator receptor (uPAR) message by hypoxia. Exp Cell Res 255: 250-257 entities is quite variable and the results from one entity could not necessarily be extrapolated to another. But since up-regulation of the uPA system is a relatively common feature in many solid tumours, interferences with this system may be a possible therapeutic approach in at least some entities. It may be possible to combine inhibitors of the uPA system with radiotherapy, as these modalities represent different therapeutic principles and therefore only limited overlapping toxicity should be expected.

\section{ACKNOWLEDGEMENTS}

We thank Dr DK Kelleher and PD Dr L Plasswilm for assistance in preparing the manuscript and helpful discussions.
Nordsmark M, Overgaard J (2000) A confirmatory prognostic study on oxygenation status and loco-regional control in advanced head and neck squamous cell carcinoma treated by radiation therapy. Radiother Oncol 57: $39-43$

Nordsmark M, Alsner J, Keller J, Nielsen OS, Jensen OM, Horsman MR, Overgaard J (2001) Hypoxia in human soft tissue sarcomas: adverse impact on survival and no association with p53 mutations. Br J Cancer 84: $1070-$ 1075

Raff T, van der Giet M, Endemann D, Wiederholt T, Paul M (1997) Design and testing of beta-actin primers for RT-PCR that do not co-amplify processed pseudogenes. Biotechniques 23: 456-460

Reuning U, Magdolen V, Wilhelm O, Fischer K, Lutz V, Graeff H, Schmitt M (1998) Multifunctional potential of the plasminogen activation system in tumor invasion and metastasis (review). Int J Oncol 13: 893-906

Rofstad EK (2000) Microenvironment-induced cancer metastasis. Int J Radiat Biol 76: $589-605$

Semenza GL (2000) HIF-1: mediator of physiological and pathophysiological responses to hypoxia. J Appl Physiol 88: $1474-1480$

Sordat I, Chaubert P, Protiva P, Guillou L, Mazzucchelli L, Saraga E, Benhattar J, Tran-Thang C, Blum AL, Dorta G, Sordat B (1997) In situ stromal expression of the urokinase/plasmin system correlates with epithelial dysplasia in colorectal adenomas. Am J Pathol 150: 283-295

Stahl AMB (1997) Melanoma cell migration on vitronectin: regulation by components of the plasminogen activation system. Int $J$ Cancer 71: $116-122$

Sugiura Y, Ma L, Sun B, Shimada H, Laug WE, Seeger RC, DeClerck Y (1999) The plasminogen-plasminogen activator (PA) system in neuroblastoma: role of PA inhibitor-1 in metastasis. Cancer Res 59: $1327-1336$

Sundfor KL, H Rofstad EK (1998) Tumor hypoxia and vascular density as predictors of metastasis in squamous cell carcinoma of the uterine cervix. Br J Cancer 78: $822-827$

Thews O, Kelleher D, Vaupel P (1997) Tumor oxygenation under normobaric and hyperbaric hyperoxia. Impact of various inspiratory $\mathrm{CO}_{2}$ concentrations. Adv Exp Med Biol 428: 79-87

Vassalli JBD (1987) Amiloride selectively inhibits the urokinase-type plasminogen activator. FEBS Lett 214: $187-191$

Vaupel P, Kallinowski F, Okunieff P (1989) Blood flow, oxygen and nutrient supply, and metabolic microenvironment of human tumors: a review. Cancer Res 49: 6449-6465

Vaupel P, Schlenger K, Höckel M (1992) Blood flow and tissue oxygenation of human tumors: an update. Adv Exp Med Biol 317: 139-151

Vaupel P, Thews O, Kelleher DK, Höckel M (1998) Current status of knowledge and critical issues in tumor oxygenation. Results from 25 years research in tumor pathophysiology. Adv Exp Med Biol 454: 591-602

Workman P, Twentyman P, Balkwill F et al (1998) United Kingdom Committee on Cancer Research (UKCCCR) Guidelines for the welfare of animals in experimental neoplasia (second edition). Br J Cancer 77: $1-10$

Yamamoto MS, Sawaya R, Mohanam S, Loskutoff DJ, Bruner JM, Rao VH, Kazunari O, Tomonaga M, Nicolson GL, Rao JS (1994) Expression and localization for plasminogen activator inhibitor type 1 in human astrocytoma in vivo. Cancer Res 54: 3329-3332 